\title{
ESTUDO EXPERIMENTAL DO DESEMPENHO DE PAVIMENTOS PERMEÁVEIS COMO ALTERNATIVA DE REDUÇÃO DO ESCOAMENTO SUPERFICIAL EM ÁREAS URBANAS
}

\author{
EXPERIMENTAL STUDY OF PERFORMANCE FLOOR PERFORMANCE AS AN \\ ALTERNATIVE OF SURFACE FLOW REDUCTION IN URBAN AREAS
}

\author{
Enicléia Nunes de Sousa Barros ${ }^{1}$, Saymon Martin Boaventura ${ }^{2}$
}

Recebido em 20 de dezembro de 2019; aceito em 16 de abril de 2020; disponível on-line em 05 de junho de 2020.

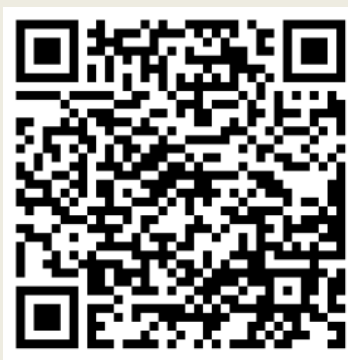

PALAVRAS CHAVE:

Impermeabilização;

Uso do solo;

Pavimento permeável;

Escoamento superficial;

Concreto poroso;

\section{KEYWORDS:}

Waterproofing;

Use of the soil;

Permeable floor;

Surface runoff;

Porous concrete;

\footnotetext{
* Contato com os autores:
}

${ }^{1}$ enicleiajc@hotmail.com ( E. N. S Barros )

Engenheira civil, mestre em Ciências Florestais e Ambientais, Professora Assistente, UNIRG - Universidade de Gurupi.

${ }^{2}$ saymonboaventura18@gmail.com (S. M. Boaventura)

Graduando em engenharia civil, UNIRG - Universidade de Gurupi.
ABSTRACT: The process of urbanization of cities without the adequate planning of land use causes a growing waterproofing of this, leading to constant floods in urban centers. It is understood that traditional drainage systems solve only part of the problem, as they do not act on causes but only on the effects. In this sense, the present work aims to evaluate the performance of the permeable pavement in relation to the infiltration capacity of rainwater, aiming at reducing surface runoff in urban areas; for this, the simulation was performed rains to obtain the flow through the Palmas-TO precipitation equation, where it was possible to measure infiltration and flow parameters; blocks were also produced and tested in porous concrete to assess their ability to infiltrate. In the simulation carried out on the permeable pavement in interlocked blocks it was observed that precipitation was absorbed in the initial 9 minutes; already in the simulation carried out on the leaked blocks it was noticed that in this practically no surface runoff occurred. The porous concrete blocks demonstrated an excellent infiltration capacity, managing to accommodate 7.2 liters inside, which means an instant infiltration of $7.2 \mathrm{~mm}$ of rain. 


\section{INTRODUÇÃO}

O processo de urbanização das cidades, sem o adequado planejamento de uso do solo, provoca uma crescente impermeabilização dos solos. É possível estabelecer uma comparação clara para o entendimento desse processo: em áreas com cobertura florestal, há uma infiltração da chuva em torno de $95 \%$, por outro lado em áreas urbanas este percentual cai para $5 \%$. Este problema torna-se ainda mais grave pelo efeito das chamadas "ilhas de calor", onde com o aumento significativo de temperatura em áreas densamente povoadas tem-se a intensificação das precipitações.

Diante do problema das cheias, verificase que os tradicionais sistemas de drenagem, tais como: calhas, sarjetas, bocas de lobo e retificação da calha do rio, objetivam apenas se livrarem da água o mais rápido possível transferindo o problema da cheia para um ponto a jusante solucionando apenas parte do problema. É necessário agir nas causas e não apenas nos efeitos.

As prefeituras, com o objetivo de controlar as áreas urbanas impermeáveis, tem exigido um percentual de $15 \%$ a $30 \%$ do terreno sem pavimentação, destinado à infiltração das águas pluviais. Contudo nem sempre é possível facilmente atender este requisito. Uma forma de atender a legislação da cidade e ao mesmo tempo não perder área pavimentada é com a utilização dos pavimentos permeáveis, que por sua vez possibilitam a infiltração.

Atualmente, estão sendo desenvolvidas em todo o mundo, principalmente em países desenvolvidos, novas ideias em relação a gerenciamento de águas pluviais em centros urbanos. As denominadas "best management practices" (BMPs), tem por finalidade o amortecimento das cheias a partir da origem do problema e se baseiam em microreservatórios de acumulação, e aumento de áreas permeáveis. Um dos princípios desse sistema é tratar das águas pluviais onde elas caem, evitando seu deslocamento, aumento de volume e velocidade.

Os pavimentos permeáveis surgem como alternativa para reduzir os impactos da impermeabilização dos solos nos centros urbanos. Estes podem ser aplicados como passeios, calçadas, estacionamentos, pátios residenciais, comerciais e industriais vias de tráfego leve, ou seja, para utilidades onde não há grande solicitação de carga. Ao mesmo tempo em que servem de pavimentação, possibilitam a infiltração da água.

Os pavimentos permeáveis possuem vazios em sua estrutura, onde a água pode penetrar facilmente. Existem basicamente dois tipos de pavimento: pavimentos modulares e pavimento poroso; o primeiro utiliza-se das suas juntas para a infiltração das chuvas, já no segundo a água penetra nos poros existentes em sua estrutura. Estes pavimentos reduzem 0 escoamento superficial em até $100 \%$, dependendo da intensidade da chuva.

\section{OBJETIVO}

Avaliar o desempenho do pavimento permeável em relação à capacidade de infiltração das águas pluviais, visando à redução do escoamento superficial em áreas urbanas.

\section{REFERÊNCIA BIBLIOGRÁFICA}

\subsection{PAVIMENTO PERMEÁVEL}

A busca por tecnologias alternativas, para - problema das cheias nos centros urbanos, começou a partir de 1970 na Europa e América do Norte. O processo de urbanização desordenado leva à impermeabilização dos solos nas grandes cidades e por isso acontecem as inundações (MOLINA et al., 2018). Nesse sentido Batista e Nascimento (2005) apresentam medidas não estruturais compensatórias para somar-se ao sistema clássico de drenagem, entre elas estão os pavimentos porosos ou permeáveis. 
Segundo Jabur et al. (2015) a impermeabilização do solo urbano somada ao efeito da falta de planejamento urbano adequado, modificam o ciclo hidrológico no que se refere à qualidade e volume de água, gerando consequências com alto custo. $\mathrm{O}$ método tradicionalmente utilizado que consiste na implantação de tubulações de forma isolada, se for aplicada como única alternativa de drenagem torna-se uma concepção equivocada, pois acelera a velocidade do escoamento superficial e aumenta significativamente os picos de vazão de águas pluviais até os pontos a jusante. Essa técnica mostra-se ineficiente na medida em que apenas transfere os problemas de inundações e alagamentos de um ponto a outro das cidades (BEUX et al., 2015).

Entende-se por pavimento permeável um dispositivo que possibilita a infiltração, onde o escoamento das águas pluviais é conduzido, através de uma superfície permeável, a um reservatório de pedras localizado abaixo da superfície do terreno (Urbonas e Stahre, 1993). Segundo Araújo (2000) os pavimentos permeáveis são constituídos por uma camada de agregado fino ou médio e outra sob esta de agregado graúdo mais a camada superior do pavimento permeável.
Conforme a Figura 1 abaixo, o escoamento superficial infiltra no revestimento poroso, com espessura variando de 5 a $10 \mathrm{~cm}$, passa por uma camada de agregado fino ou médio, de $1,25 \mathrm{~cm}$ de diâmetro e espessura de $2,5 \mathrm{~cm}$, e é conduzido ao reservatório de pedras, com agregados de 3,8 a 7,6 cm de diâmetro e espessura mínima de $15 \mathrm{~cm}$. Estando no neste reservatório a água poderá ser infiltrada ou coletada por tubos de drenagem. (Araújo, 2000 p.21).

Com a utilização dos pavimentos permeáveis, é possível reduzir o volume de escoamento superficial, desde que sejam bem utilizados, respeitando seus limites físicos de carga, e mantendo uma manutenção preventiva periodicamente. Além disso, também atuam no controle da poluição, e contribuem para a recarga de águas subterrâneas (GONÇALVES et al., 2014).

Segundo Azzout et al. (1994) existe uma variante da utilidade dos reservatório de pedras, onde a saída de água não se dá por infiltração, mas pela rede de drenagem, trabalhando com uma estrutura de retenção e não de infiltração; sendo uma alternativa viável para solos com pouca permeabilidade ou sensíveis à presença de água.

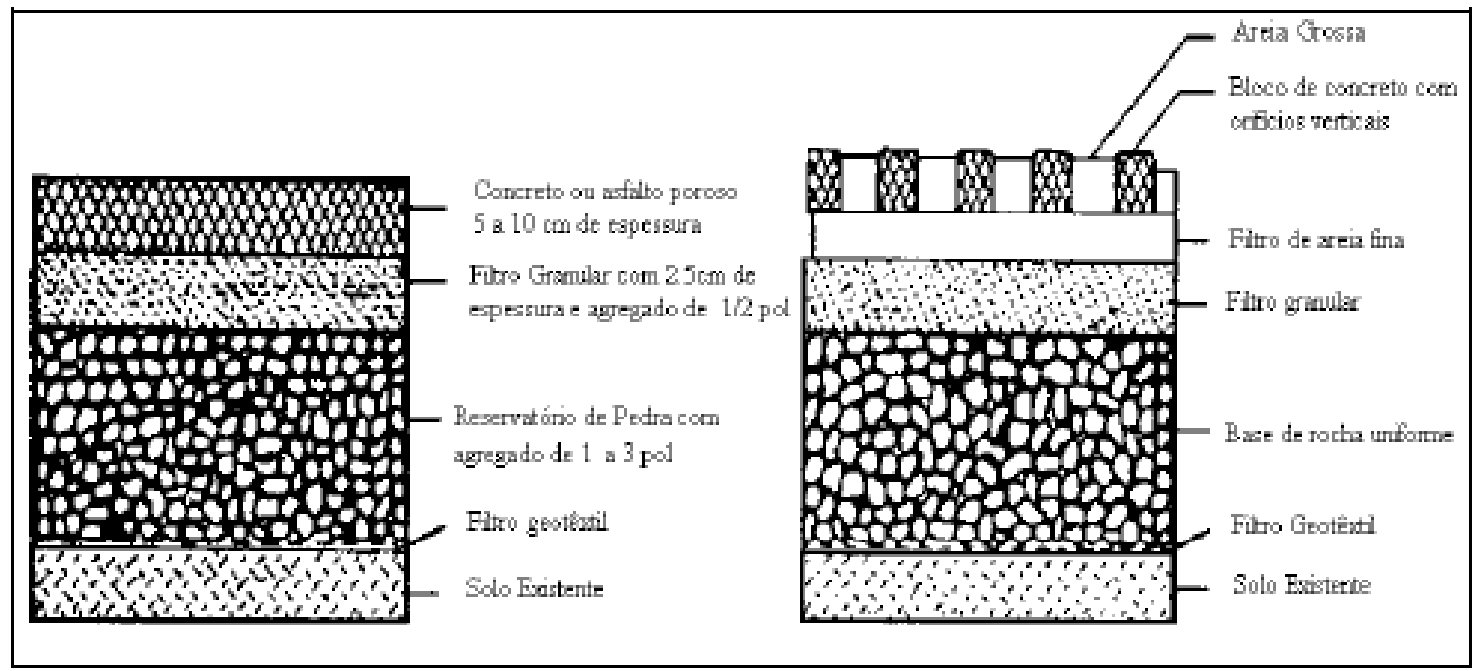

FIGURA 1- Pavimentos permeáveis

Fonte: adaptado de Urbonas e Stahre, 1993 
Devido à baixa resistência do pavimento poroso, o mesmo não pode ser utilizado em pista de rolamento de veículos. Nesse sentido Gonçalves et al., (2014) recomenda sua utilização em espaços específicos, tais como: vias de tráfego leve, estacionamentos, calçadões, praças e quadras de esporte.

No que se refere à estrutura física do pavimento permeável verifica-se que o mesmo se assemelha à do pavimento convencional, apenas se difere porque no pavimento poroso não há a utilização da areia fina como agregado. A Figura 2 mostra as camadas do pavimento permeável.

Segundo Schueler (1987, apud Tucci, 2000, p. 352 e 353) o pavimento permeável se divide em seis camadas, ilustradas na figura 2 , e ele as define da seguinte maneira:

1. Pavimento Poroso: Camada com espessura de 6 a $10 \mathrm{~cm}$, formada por um revestimento permeável cuja principal função é a infiltração das águas pluviais e a condução destas ao reservatório de padras.

2. Camada Filtro: Camada com cerca de $2,5 \mathrm{~cm}$ de espessura, composta por agregados com $1,3 \mathrm{~cm}$ de diâmetro. O escoamento ao se infiltrar na camada de revestimento poroso, passa por este filtro de agregado graúdo. Esta camada tem como objetivo estabilizar a camada do pavimento.

3. Reservatório de Pedras: Camada com agregados graúdos, que possuem de 3,8 a $7,6 \mathrm{~cm}$ de diâmetro e sua espessura depende do volume de água que se deseja armazenar, a capacidade de armazenamento de água no reservatório de pedra está ligado diretamente à profundidade deste. $\mathrm{O}$ escoamento resultante da camada de filtro penetra no reservatório de pedras, onde o mesmo poderá infiltrar para o subsolo ou ser coletado por tubos de drenagem quando o solo for impermeável.

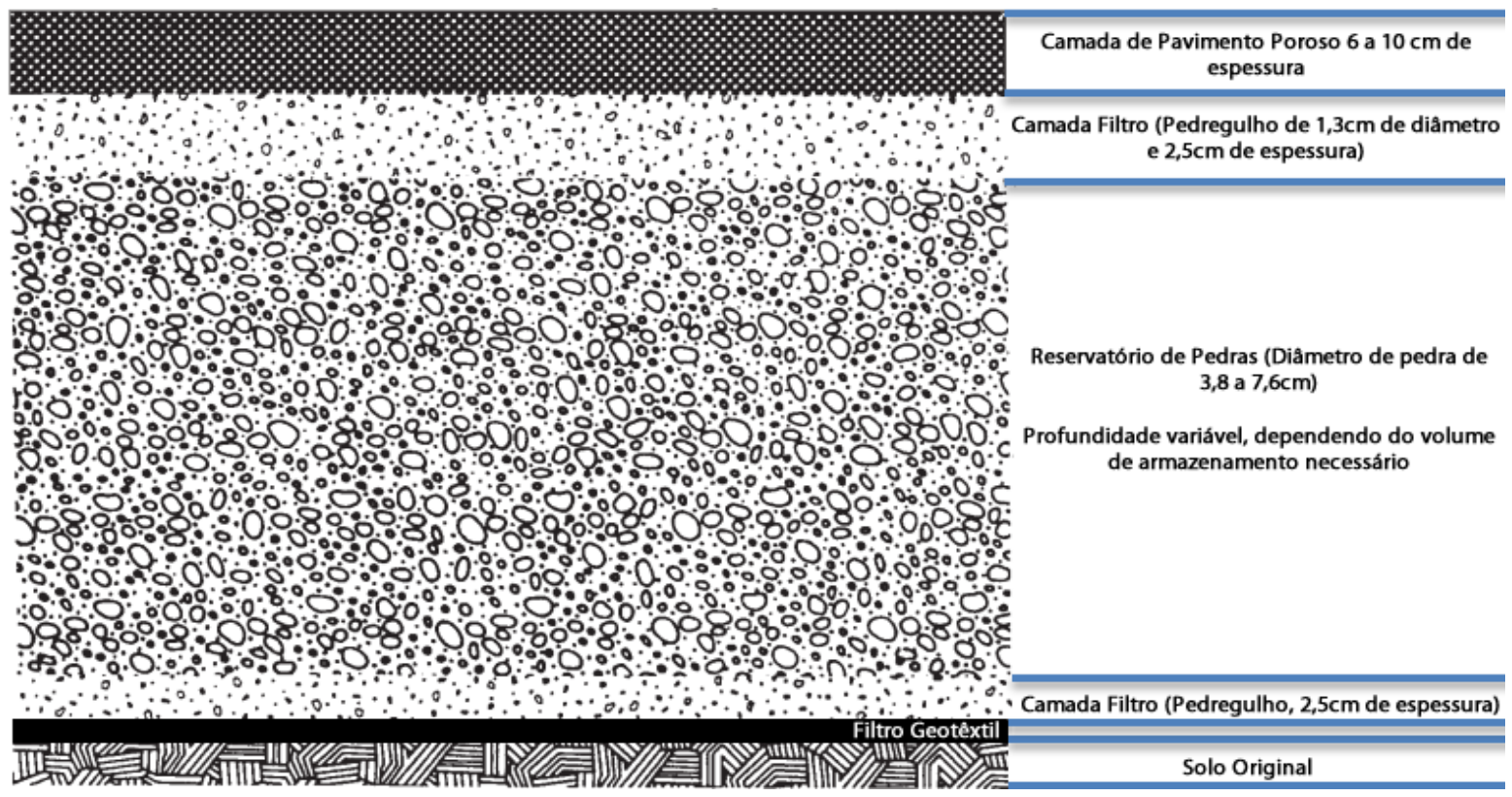

FIGURA 2 - Estrutura do Pavimento Permeável

Fonte: Adaptado de Schueler, 1987 
4. Camada Filtro: Camada com espessura de aproximadamente $2,5 \mathrm{~cm}$, sua finalidade principal é promover a ligação do reservatório de pedras com o filtro geotêxtil.

5. Filtro Geotêxtil: A finalidade do filtro geotêxtil é impedir que partículas do solo penetrem no reservatório de pedras, ocasionando 0 entupimento dos poros e impedindo a passagem da água.

6. Solo original: É a camada de solo sobre o qual as demais camadas serão construídas. É necessário que este solo tenha uma boa condutibilidade hidráulica para que a água do reservatório de pedras possa ser completamente infiltrada. Segundo Urbonas e Stahre (1993) é importante que o nível do lençol freático esteja a pelo menos $1,20 \mathrm{~m}$ de distância da base do pavimento.

O pavimento permeável precisa de manutenção regularmente com mão-de-obra especializada, o que pode ter um custo elevado, para evitar o entupimento dos poros e a inutilidade do sistema. Por esse motivo, o uso desta tecnologia tem suas limitações de uso no controle do escoamento, além do risco de colmatação da estrutura, ainda pode haver a contaminação das águas subterrâneas.

Urbonas e Stahre (1993) afirmam não haver limitações para o uso do pavimento permeável, exceto quando existe a baixa permeabilidade do solo impossibilitando a infiltração da água, ou mesmo quando o nível do lençol freático for alto e ainda se houver uma camada completamente impermeável. Neste caso a alternativa sugerida pelo autor é: colocar uma membrana impermeável entre o reservatório e o solo, sendo assim o reservatório funcionará como um poço de detenção; para que esse sistema tenha um bom desempenho deve ser utilizados tubos de drenagem espaçados de 3 a $8 \mathrm{~m}$ e também prever o esgotamento do volume de águas num período de 6 a 12 horas.

Segundo Araújo (2000 p. 22) a utilização dos pavimentos permeáveis pode proporcionar uma redução significativa no escoamento superficial, desde que seja utilizado corretamente, e sua execução respeite as especificações técnicas, além de precisar de manutenção periódica em todo o sistema. $\mathrm{O}$ autor ressalta que as principais limitações destes dispositivo são:

- quando a água drenada encontra-se fortemente contaminada, causando impacto sobre as águas subterrâneas;

- falta de cuidados na construção, sem preocupação com as especificações técnicas e falta de manutenção qualificada, que podem entupir os poros, tornando o dispositivo ineficiente.

\subsection{Opções de Revestimento}

Segundo Urbonas e Stahre (1993) os pavimentos permeáveis estão classificados em três tipos:

- Pavimento de concreto poroso;

- Pavimento de asfalto poroso;

- Pavimento de bloco de concreto vazado, preenchidos com areia ou vegetação rasteira.

Estes dois primeiros, concreto poroso e asfalto poroso, são preparados similarmente ao concreto e asfalto tradicionais, a única diferença entre eles é que o concreto poroso e o asfalto poroso não utilizam agregados finos (areia) na sua composição, o que permite a estes ter porosidade necessária à infiltração das águas pluviais.

Segundo (Yang e Jiang, 2003) o concreto poroso possui baixa resistência, atingindo na maioria das vezes valores de resistência à compressão entre 20 e $30 \mathrm{MPa}$. Por esse motivo, 
esse sistema é indicado apenas para locais onde há baixa solicitação de carregamento, ou seja, submetidos a baixas tensões, como por exemplo: quadras, passeios, calçadas e estacionamentos. Existem pesquisadores que tem buscado, por meio do uso de agregados selecionados, adições de minerais finos e intensificadores orgânicos, aumentar a resistência à compressão, tração e cisalhamento. Verifica-se que nos seus experimentos, já houve certo progresso, pois foram alcançados valores de resistência a compressão de 50MPa e resistência à tração de 6Mpa.

\subsubsection{Pavimento de Concreto Poroso}

Para MAZZONETTO (2012, p.1) o concreto permeável ou poroso permite que a água das chuvas infiltre e seja armazenada nas camadas inferiores, podendo ser conduzida ao lençol freático por meio do subleito ou ser levada ao sistema de drenagem da cidade. É uma tecnologia pouco adotada no Brasil, e vem se difundindo aos poucos pelos construtores para atender ás legislações municipais que destinam parte do terreno a ser área permeável, com isso tem-se um espaço pronto para receber precipitações, evitando enchentes e realimentando o aquífero subterrâneo.

Segundo VIRGILIIS (2009, p.45),

"o concreto poroso é apropriado para suportar carregamentos de baixo volume de tráfego como em calçadas e áreas de manobra de estacionamentos residenciais, além de suportar carga de tráfego médio em estacionamentos comerciais e ruas residenciais. Poderá sob condições específicas de dimensionamento receber carregamentos de tráfego pesado. 0 concreto poroso quando acabado tem grande permeabilidade. Como desvantagem, há sempre a possibilidade de colmatação e constantes gastos com a manutenção e limpeza".

A Figura 3 ilustra o concreto poroso, como é possível observar existe um volume de vazios considerável em comparação com o concreto convencional. Fergunson B.K. (2005) afirma que o concreto poroso é uma sutil diferença na mistura tradicional do cimento Portland, pois no caso do concreto permeável, os agregados devem ter graduação uniforme. O mesmo tem alto custo inicial, mas em longo prazo este custo é minimizado. Essa tecnologia não pode ser aplicada sobre um subleito fraco, pois pode ocasionar trincas devido a movimentação da massa de solo.

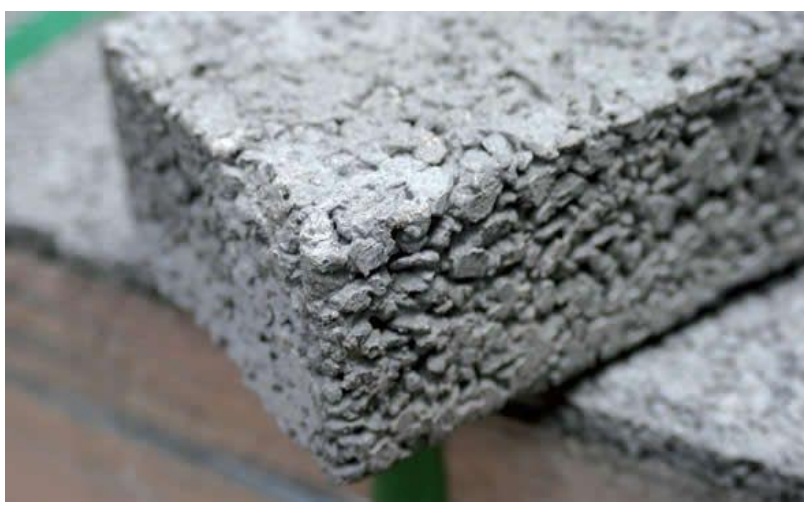

FIGURA 3 - Concreto Poroso

FONTE: Adaptado Mazzonetto, 2012, p.1

\section{Para MAZZONETTO (2012, p.1)}

"Devido à granulometria, as peças de concreto permeável, que são o método mais fácil de ser visto em uso no Brasil, são mais caras do que as convencionais. $O$ sistema inteiro de pavimentação chega a custar 35\% a mais. Mariana, da ABCP, alerta, porém, que o custo de cada projeto deve ser pensado levando em conta que o concreto permeável tem a função de pavimento e também drenagem. Além disso, em boa parte das vezes ele é utilizado para adequar o projeto à legislação, respeitando a permeabilização exigida pelos órgãos públicos".

A Figura 4 ilustra um pavimento permeável em concreto poroso que necessita de um sistema alterativo de drenagem, isso pode ocorrer quando o solo é impermeável ou parcialmente permeável (solo argiloso ou areia argilosa), ou quando tem-se um alto nível do lençol freático. 


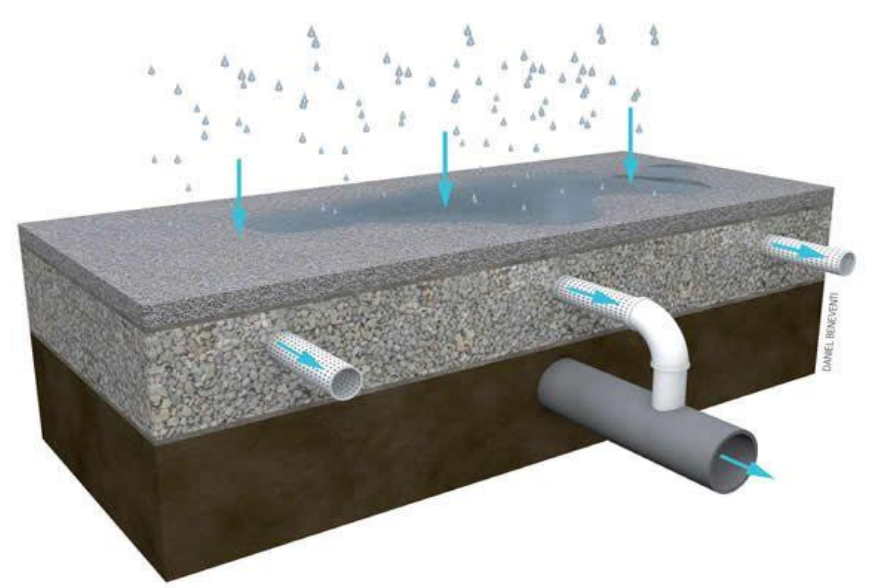

FIGURA 4 - Solução em pavimentação de concreto poroso com drenagem da água infiltrada por tubulação FONTE: Adaptado Mazzonetto, 2012, p.1.

\subsubsection{Concreto Asfáltico Poroso}

Para VIRGILIIS (2009, p.48) o concreto asfáltico poroso é uma mistura entre ligante betuminoso e agregados de diâmetros uniformes, é também uma variação do concreto asfáltico convencional, porém é susceptível ao entupimento dos poros por meio do próprio ligante. Quando o ligante é muito fluido ou quando a união entre ligante e agregado é fraca pode ocorrer a colmatação da superfície do revestimento.

A Figura 5 ilustra o concreto asfáltico poroso, observa-se os poros comparando esse pavimento com uma caneta que está sobre ele.

Segundo MAYNARD $(2012$, p.3)

"O asfalto permeável, cujo nome técnico é CPA - Camada Porosa de Atrito, um dos componentes do pavimento, é a interface entre a superfície e as camadas interiores. $E$ feito por meio de mistura usinada a quente entre agregados, cimento asfáltico, fibras e polímeros. De modo geral, o preço do asfalto permeável é mais caro que o convencional na ordem de 30\%, porém além das vantagens de abater os pico de cheia e recarregar os aquíferos ele possui característica de redução de ruído da ordem de 3 decibéis. No entanto, ele ainda não pode ser usado em vias de tráfego pesado, mas sua utilização em estacionamentos e vias de baixo volume de tráfego pode oferecer diversos benefícios".

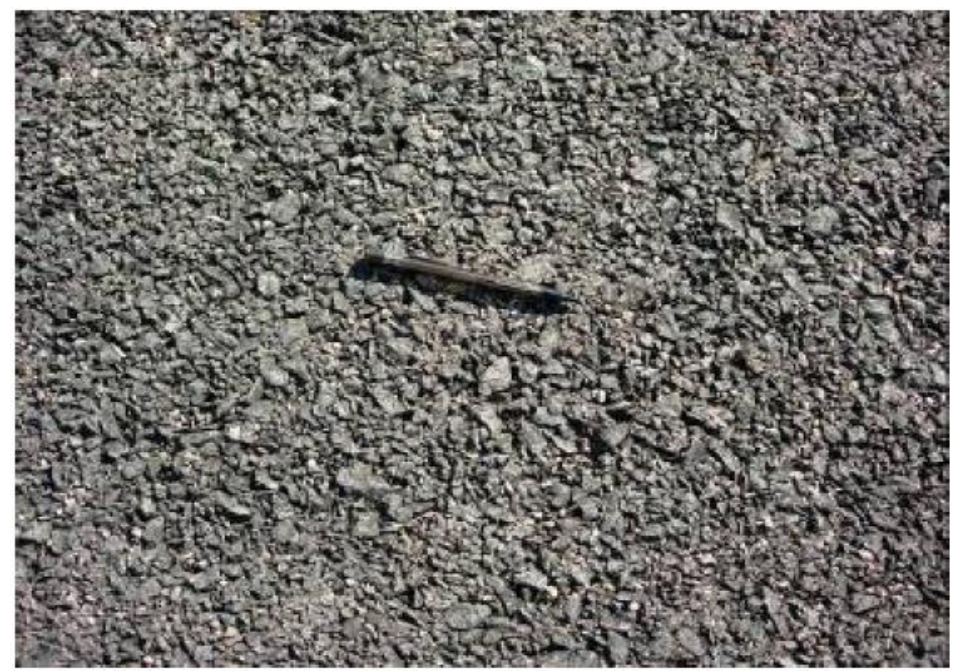

FIGURA 5 - Concreto Asfáltico Poroso

FONTE: Adaptado VIRGILIIS 2009, p.48 
A vantagem do uso do concreto asfáltico é que o mesmo serve como um filtro natural da água, através do reservatório de pedras, retendo parte da poluição atmosférica e da sujeira das próprias ruas; também reduz o chamado spray, que são os jatos de água gerados pela passagem dos automóveis no asfalto.

A Figura 6 ilustra as camadas do concreto asfáltico poroso, sendo que a primeira é o próprio pavimento permeável, seguido de uma camada de nivelamento, base de padras e manta plástica.

Segundo MARTINS (2011, p.1)

"O asfalto permeável já existia, mas ainda não era usado no Brasil. O que fizemos foi estudar a melhor forma de aplicá-lo. Incluindo uma lona plástica bem fina em contato com o solo, coberta por uma camada de pedras que depois é revestida pelo asfalto poroso. Nesse espaço, a água absorvida pode ficar armazenada por um tempo e não escoar diretamente para os córregos e rios. Restituímos de forma artificial a permeabilidade do solo que perdemos com $o$ crescimento das cidades."

\subsubsection{Blocos de Concreto Vazados}

No que se refere à execução dos blocos de concreto vazados, sabe-se que estes são colocados sobre uma camada de base granular (areia). Já os filtros geotêxtil são colocados sob a camada a de areia fina para evitar que a areia migre para a camada granular (Araújo, 2000 p. 22).

Segundo VIRGILIIS (2009, p.46), os blocos de concreto vazados são:

"Unidades de blocos de concreto desenhados em células ou aberturas que permitem o preenchimento com agregados ou gramináceos. São implantados lado a lado resultando numa superfície semelhante a uma gralha ou desenho simétrico em ângulo reto ou diagonal. Como pavimento não são relativamente econômicos. Muitos tipos são duráveis e possuem considerável vida útil. A maior parte é capaz de suportar bem a carregamentos pesados".

A Figura 7 mostra um pavimento em blocos de concreto vazados, preenchidos com grama.

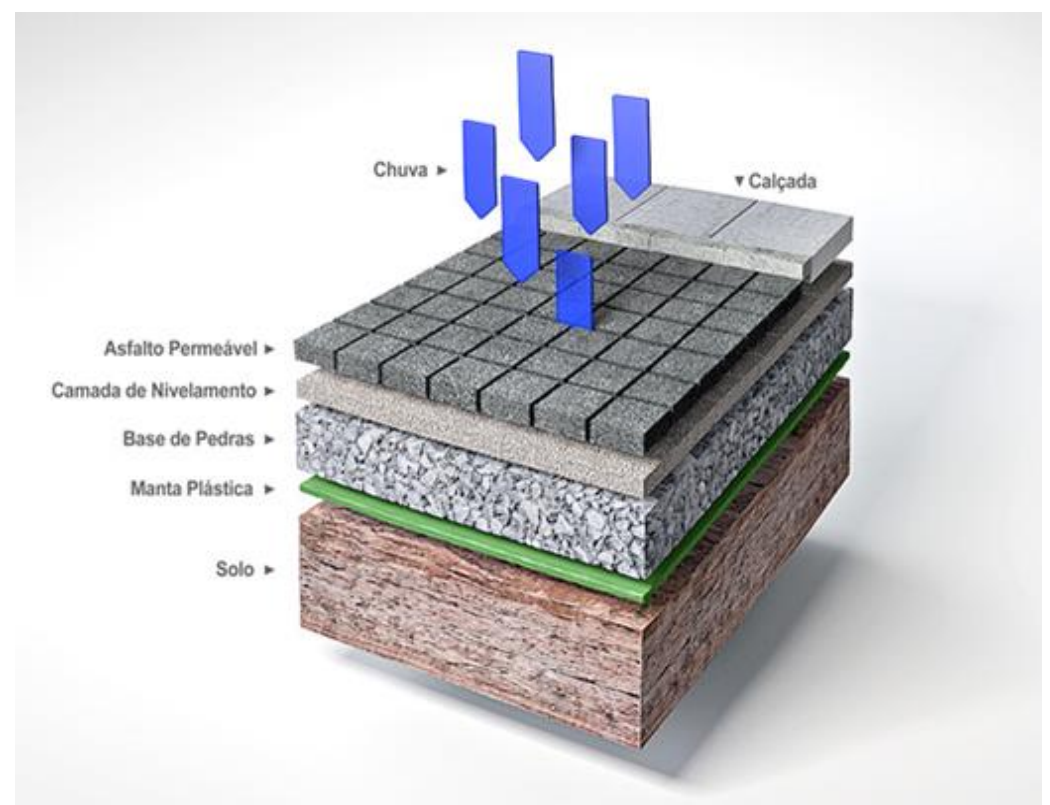

FIGURA 6 - Concreto Asfáltico Poroso

FONTE: Adaptado FONSECA, 2011 


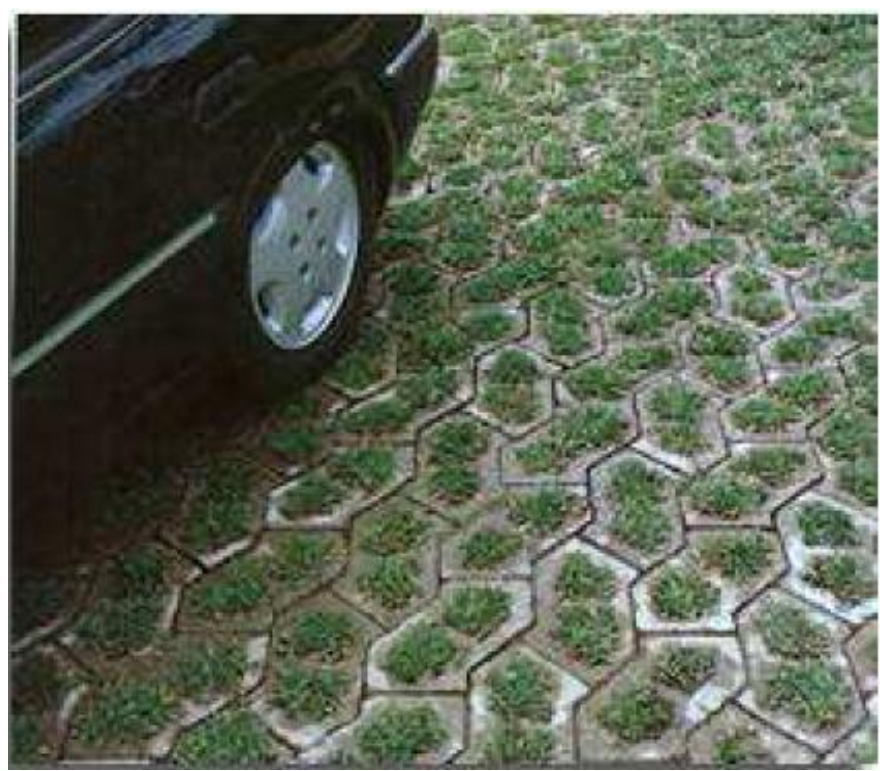

FIGURA 7 - Bloco de concreto vazado

FONNTE: Adaptado BRAGA, 2008, p. 8

Devido não haver muitas empresas que trabalham com a produção de blocos de concreto vazados, esse tipo de revestimento tem um custo elevado em relação a outros materiais. No que diz respeito a porosidade e condutibilidade hidráulica, são excelentes, porém devem trabalhar solidamente unidas e confinadas as bordas de concreto. As peças são executadas em concreto com resistência mínima de 25 Mpa (ABNT 9780/87 e ABNT 9781/87) para adquirirem boa resistência à compressão (VIRGILIIS 2009, p.46).

\subsubsection{Bloco de Concreto Intertravados}

Os blocos intertravados de concreto formam um tipo de revestimento que permite diversos tipos de tráfegos. São blocos maciços de concreto, assentados sobre camada de areia que confere ao conjunto porosidade e permeabilidade.

VIRGILLIUS (2009, p.47) afirma que:

"Muitos blocos possuem boa durabilidade e resistência, permitindo vida útil mais longa e consequentemente economia sob o aspecto custo benefício. Alguns blocos podem suportar tráfego pesado, porém são relativamente caros quando comparados a outros pavimentos. São sensiveis as deformações longitudinais, assim como as deformações na base $e$ no subleito. Quando assentados devem ser confinados a bordas rígidas, que impedem que as peças fiquem livres de tensão e possam se soltar. Geralmente são limitados nas extremidades a sarjetas ou vigotas de concreto".

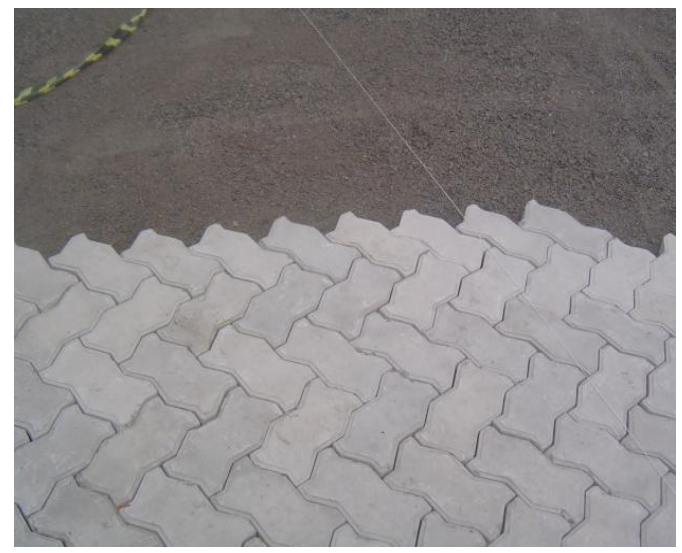

FIGURA 8 -Blocos de concreto intertravados FONTE: disponível em:

http://nascimentopisos.blogspot.com.br/

\section{METODOLOGIA}

Este trabalho foi desenvolvido por meio de uma metodologia quantitativa que analisou o desempenho de pavimentos permeáveis como alternativa de redução do escoamento superficial 
em áreas urbanas. $\mathrm{O}$ experimento foi realizado no Laboratório de Recursos Hídricos do CEULP/Ulbra, onde o simulador de precipitação fez chover sobre as camadas de pavimento permeável.

Os pavimentos escolhidos para execução dos ensaios de simulação de chuva foram:

$>$ Pavimento semipermeável: blocos de concreto industrializados com juntas de areia, conhecidos por blocos intertravados;

> Pavimentos permeáveis: blocos de concreto com orifícios verticais preenchidos com material granular e blocos de concreto poroso.

Os blocos intertravados e vazados foram adquiridos nas empresas fabricantes, já o bloco de concreto poroso, não existe à venda no mercado local, e por isso foi produzido no Laboratório de Materiais de Construção do UNIRG, com um traço de 1:6 (cimento e brita 1), nas dimensões $37,5 \times 37,5 \mathrm{~cm}$ e espessura de $15 \mathrm{~cm}$.

A precipitação simulada foi de $154,9 \mathrm{~mm} / \mathrm{h}$, baseada nos dados do software Plúvio, onde foi extraída uma média das precipitações ocorridas entre os anos de 1976 e 2010.

Foi realizada a simulações de chuva sobre os pavimentos com a finalidade de medir a infiltração e o escoamento superficial gerados. 0 simulador de chuvas utilizado nas simulações consiste em um aparelho já existente no laboratório, que possui capacidade de gerar precipitações com diferentes intensidades sobre uma área de $2 \mathrm{~m}^{2}$. A água é bombeada a uma vazão constante até 8 aspersores fixados em um ramal, 4 para cada $1 \mathrm{~m}^{2}$, existe um regulador de vazão, onde foi possível adotar precisamente a vazão de $0,3 \mathrm{~m}^{3} / \mathrm{h}$, definindo a intensidade da chuva aspergida sobre a parcela de $2 \mathrm{~m}^{2}$.

Para o bloco de concreto poroso, foram utilizadas apenas uma balança e uma manta plástica. A balança pertence ao Laboratório de Materiais de Construção, local onde ocorreu esse segundo experimento. A escolha dos blocos de concreto intertravados ocorreu em função de que tal superfície está com o uso em expansão, e por apresentarem uma boa taxa de infiltração de água por suas juntas de areia, com largura média de $1 \mathrm{~cm}$, comparados a outros revestimentos considerados impermeáveis. Os blocos vazados, também conhecidos como piso grama, foram preenchidos com pedriscos, para fins de experimento.

O Concreto poroso, também conhecido como concreto sem finos, deve ser pouco adensável. Estes têm baixo valor de coesão; nesse sentido as formas devem permanecer na estrutura até que mesma tenha desenvolvido uma resistência suficiente. A cura úmida é imprescindível, especialmente em climas seco, como é o caso do Tocantins.

Foi efetuada simulação da chuva de projeto com intensidade de $154,9(\mathrm{~mm} / \mathrm{h})$, sobre as parcelas blocos de concreto intertravados e blocos de concreto vazados, conforme expressa a Figura 9.

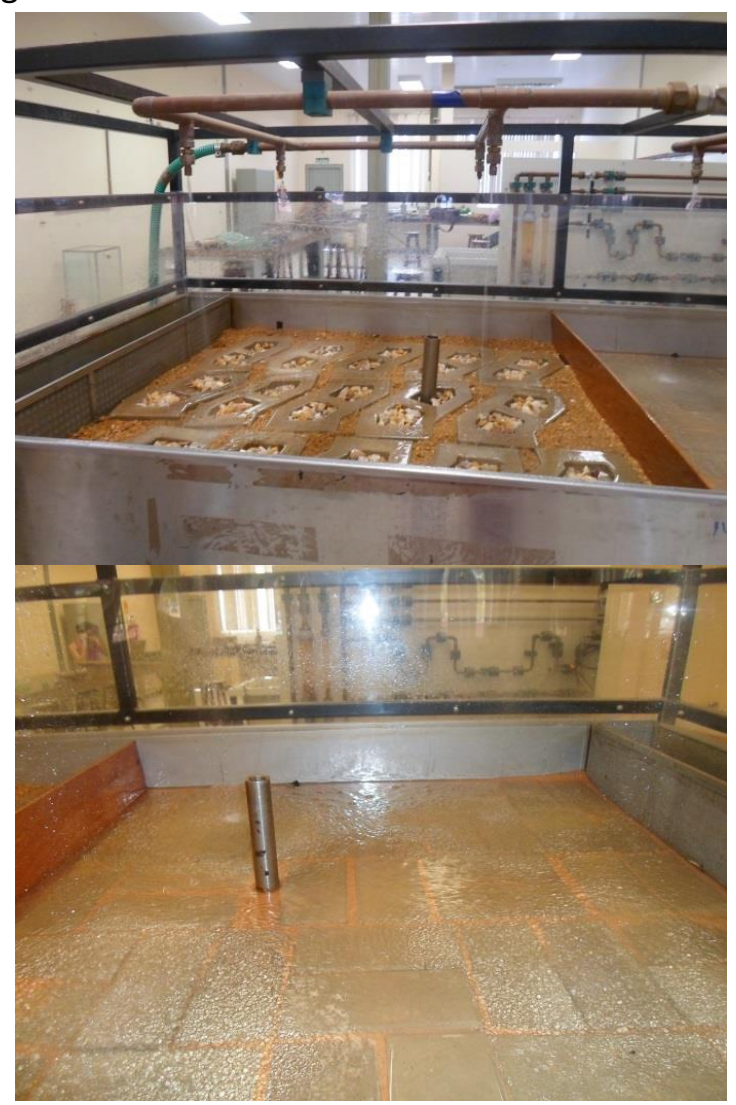

FIGURA 9 - Simulação de chuva sobre os pavimentos em blocos intertravados e vazados 
O tempo de chuva foi de 30 minutos, pois entende-se ser o tempo necessário para a boa observação do desempenho dos pavimentos testados frente à chuva de projeto.

A intensidade simulada de 154,9 foi utilizada considerando a realidade local do município de Palmas-TO.

A vazão precipitada foi de $0,3 \mathrm{~m}^{3} / \mathrm{h}$. Conforme a chuva de projeto foi arredondada para esse valor para fins de precisão no momento de regular o equipamento.

Considerando uma precipitação de $0,3 \mathrm{~m}^{3} / \mathrm{h}$, tem-se uma chuva total de 5 litros por minuto, que dividido entre os dois pavimentos, tem-se 2,5 litros por minutos para cada um.

Em um primeiro momento foi aferido o peso do bloco em concreto poroso no estado seco, obtendo-se o seguinte resultado: $32,80 \mathrm{Kg}$, conforme ilustrado na Figura 10.

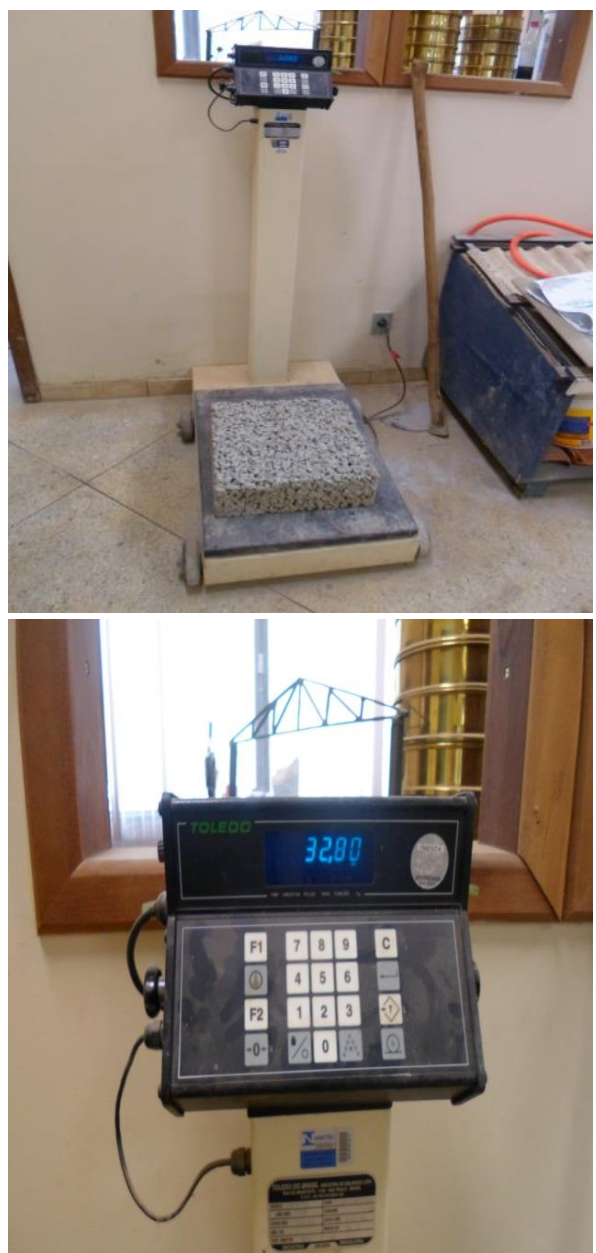

FIGURA 10 - Peso do bloco em concreto poroso no estado seco.
Em um segundo momento foi aferido o peso do mesmo bloco no estado saturado, obtendo-se o seguinte valor: $40,50 \mathrm{~kg}$, conforme ilustra a Figura 14.

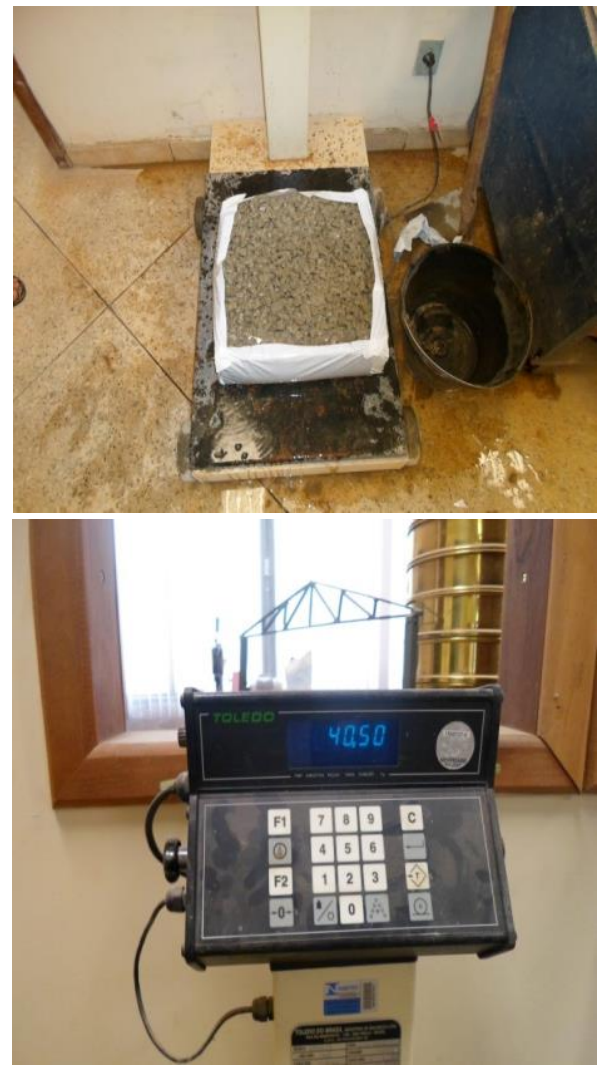

FIGURA 11 - Peso do bloco em concreto poroso no estado saturado

Tem-se a seguinte equação:

$$
\begin{aligned}
& V a=\text { Psaturado }- \text { Pseco } \\
& V a=40,50-32,80 \\
& V a=7,7 \mathrm{~kg}
\end{aligned}
$$

Assim foi obtido um valor de $7,7 \mathrm{Kg}$, o que equivale a 7,7 litros de água, considerando a relação 1 litro de água $=1 \mathrm{Kg}$. Contudo acredita-se uma perda em torno de 0,5 litros, considerando a água que derramou sobre a balança e também um pequeno deslocamento da manta plástica. Nesse sentido, o volume de água que o bloco comportou em seus poros foi de 7,2 litros.

\section{RESULTADOS E DISCUSSÕES}

O resumo dos resultados da simulação pode ser observado na tabela 1. 


\begin{tabular}{|c|c|c|}
\hline \multicolumn{3}{|c|}{ RESULTADOS DA SIMULAÇÃO DE CHUVA SOBRE OS PAVIMENTOS } \\
\hline Parâmetros & $\begin{array}{l}\text { Blocos de Concreto } \\
\text { Intertravados }\left(1 \mathrm{~m}^{2}\right)\end{array}$ & $\begin{array}{l}\text { Blocos de Concreto } \\
\text { Vazados }\left(1 \mathrm{~m}^{2}\right)\end{array}$ \\
\hline Tempo de chuva (min) & 30 & 30 \\
\hline Intensidade simulada $(\mathrm{mm} / \mathrm{h})$ & 154,9 & 154,9 \\
\hline Vazão Precipitada $\left(\mathrm{m}^{3} / \mathrm{h}\right)$ & 0,3 & 0,3 \\
\hline Chuva total (I/min) & 2,5 & 2,5 \\
\hline $\begin{array}{l}\text { Tempo Para a Geração de Escoamento } \\
\qquad \text { (min) }\end{array}$ & 9 & 27 \\
\hline Tempo Para Drenagem (min) & 7 & 13 \\
\hline Infiltração (I) & 22,5 & 67,5 \\
\hline Escoamento/Drenagem & 52,5 & 7,5 \\
\hline
\end{tabular}

Observa-se que o pavimento em blocos intertravados gerou escoamento aos 9 minutos de chuva, isso se deve ao fato de que a absorção de água acontece apenas pelas juntas de areia. Contudo pode-se afirmar que há uma significativa redução do escoamento quando comparado a pavimentos impermeáveis; nesse sentido sugerese o uso deste pavimento em áreas urbanas em substituição a pavimentos impermeáveis, tais como: estacionamentos, calçadas, passeios, ciclovias, pistas para pedestres, etc.

O pavimento em blocos vazados apresentou um tempo para geração de escoamento de 27 minutos, o que o torna um ótimo aliado na redução do escoamento. Verificase que este tipo de pavimento permite a infiltração de grande quantidade de água, pois a maior parte do fluido penetra pelos vazados existentes nos blocos, e ainda conta com juntas pelas quais também a água pode infiltrar. Esse tipo de pavimento, também conhecido como piso grama, pode ser usado com os vazados preenchidos com grama ou pedriscos; nesse sentido é mais indicado para garagens, estacionamentos e calçadas.

Em relação ao tempo de drenagem observa-se que os blocos intertravados levaram menos tempo para drenar, isso se deve ao fato de que o escoamento gerado nesse pavimento foi bem maior do que no segundo, que por sua vez teve a maior parte do seu volume infiltrado. Por isso entende-se que a drenagem do volume escoado ocorre bem mais rápida, em comparação à drenagem do volume infiltrado.

No pavimento de concreto poroso obteve-se um valor de $7,7 \mathrm{Kg}$, o que equivale a 7,7 litros de água, considerando a relação $1 \mathrm{~kg}=1$ litro de água. Contudo acrescenta-se uma perda em torno de 0,5 litros, considerando a água que derramou sobre a balança e também um pequeno deslocamento da manta plástica. Nesse sentido, o volume de água que o bloco comportou em seus poros foi de 7,2 litros.

Tendo em vista as dimensões do bloco em concreto poroso de $37,5 \mathrm{~cm} \times 37,5 \mathrm{~cm} \times 14 \mathrm{~cm}$, que equivale a um volume de 19,69 litros, pode-se afirmar que o volume de poros corresponde a $36,57 \%$ do volume total do bloco.

O pavimento em concreto poroso é muito eficaz na redução do escoamento superficial; recomenda-se a sua utilização em espaços onde não há solicitação de cargas elevadas, pois devido à falta de agregado miúdo em sua composição, há uma baixa na sua 
resistência. Espaços como estacionamentos, passeios, calçadas, ciclovias etc., são ideais para o uso deste pavimento.

\section{CONCLUSÕES}

O presente trabalho descreve um estudo experimental do uso de pavimento permeável em áreas urbanas, onde prosseguiu-se ao ensaio de simulação de chuva sobre os pavimentos e posteriormente mediu-se a capacidade de infiltração de cada um deles, com o objetivo de analisar experimentalmente os escoamentos das águas superficiais em seus aspectos qualitativos e quantitativos.

Inicialmente na simulação efetuada sobre o pavimento permeável em blocos intertravados acredita-se que o escoamento superficial gerado seja inferior quando comparado a uma superfície pavimentada em concreto ou em asfalto, isso por que o mesmo absorveu a precipitação até os 9 minutos iniciais, nesse sentido o seu uso em áreas urbanas pode contribuir para o controle da geração de escoamento superficial quando instalados em substituição a pavimentos impermeáveis.

$\mathrm{Na}$ simulação realizada sobre os blocos vazados percebeu-se que neste praticamente não ocorreu escoamento superficial. Os blocos em concreto poroso demonstraram uma ótima capacidade de infiltração, pois possuem um volume de vazios considerado bom, conseguindo comportar em seu interior 7,2 litros, o que significa uma infiltração instantânea de $7,2 \mathrm{~mm}$ de chuva. Por essas razões sugere-se que ambos os pavimentos sejam utilizados em estacionamentos para veículos leves, devido a sua baixa capacidade de carga, especialmente em áreas de shopping centers e grandes supermercados, uma vez que eles demonstram serem tecnologias altamente desenvolvidas para o controle dos volumes escoados.

Vale lembrar que estes pavimentos testados precisam de manutenção constante e periodicamente, o que confere um maior custo.
Contudo esse valor pode ser deduzido pela redução da drenagem resultante da área, tendo em vista que grande parte do volume se infiltrará. Finalmente afirma-se a importância da utilização destes pavimentos, em substituição a superfícies impermeáveis, pois o uso dos pavimentos permeáveis apresentará uma melhoria significativa para o problema das inundações urbanas.

\section{REFERÊNCIAS BIBLIOGRÁFICAS}

AZZOUT, Y.; BARRAU ,S.; CRES, F. N.; ALFAKIH, E. Techniques Alternatives en Assainissement Pluvial, Paris: Technique et Documentation, 1994, Lavoisier, $372 p$

BATISTA, M.; NASCIMENTO, N.; BARRAUD, S. Técnicas Compensatórias em Drenagem Urbana, Porto Alegre, ABRH (2005) 266.p.

BEUX, F. et al. Métodos alternativos de drenagem a partir da retenção e infiltração das águas de chuvas no solo, visando a redução das enchentes urbanas. 2015. Disponível em https://www.amigosdanatureza.org.br/publicacoes/ind ex.php/gerenciamento_de_cid

FONSECA, M. Asfalto permeável, Blog: A construção coletiva do nosso futuro: Uma conversa sobre inovação, cidadania e democracia, 2011. Disponível em: http://blog.movimentominas.com.br/blog/asfaltopermeavel

GOLDENFUM, J. A.; SILVEIRA, A. L. L.; AGRA, S. G. Estudo Experimental de Pavimentos Permeáveis no Controle do Escoamento Superficial na Fonte UFRGS/IPH - PMPA/SMOV, Porto Alegre, 2003.

GONÇALVES, A. et al. Pavimentos Permeáveis e sua influência sobre a drenagem. 2014. Disponível em: www.pha.poli.usp.br/LeArq.aspx?id_arq=11805

JABUR, A. et al. Determinação da capacidade de infiltração de pavimentos permeáveis. 2015. Disponível em: .

https://www.researchgate.net/publication/305306606 Determinacao_da_capacidade_de_infiltracao_de_pavi mentos_permeaveis_Determination_of_the_infiltration _capacity_of_permeable_pavements

MAYNARD, L., SANTOS, M. Siurb normatiza utilização de asfalto permeável, para evitar enchentes; Diário Oficial da Cidade de São Paulo, São Paulo, 2012. Disponível em: http://www.apemec.com.br/arquivos_pdf/noticias/siur b_normatiza_utilizacao_asfalto_enchentes.pdf 
MAZZONETTO, C., Concreto Permeável: Alternativa para aumentar a permeabilidade de pavimentos submetidos a cargas reduzidas, sistema demanda cuidados de especificação, instalação e manutenção, Revista PINI, 2012. Disponível em: http://www.infraestruturaurbana.com.br/solucoestecni cas/13/artigo254488-2.asp

MOLINA, A. et al. Sistemas de drenagem em praças, parques e outras áreas peatonais urbanas visando amortecer inundações. 2018. Disponível em: . Acesso em: 20/01/2019.

SCHULER.T. Contrilling Urban Runoff: A pratical manual for Planning and Designing Urban BMP's , 1987.

TUCCI, C. E. M, Porto, R. L., Barros, M. T., Drenagem Urbana, Editora da Universidade, ABRH, Porto Alegre, 1997, 428 pg.

URBONAS,B. e STAHRE,P. "Storm water Best Management Practices and Detention" Prentice Hall, Englewood Cliffs, New Jersey, (1993), 450p.

VIRGILIIS, A. L. C. Procedimentos de projeto e execução de pavimentos permeáveis visando retenção e amortecimento de picos de cheias / ed.:rev. São Paulo, 2009, 191.p.

YANG, J.; JIANG, G. Experimental study on properties of pervious concrete pavimeent materials. Cement and Concrete Rsearch, 381- 383. 2003. 